Hispania Sacra, LX

122, julio-diciembre 2008, 685-701, ISSN: 0018-215-X

\title{
MUNIO, OBISPO DE CALAHORRA, 1066 A 1080, ¿DEFENSOR DEL RITO MOZÁRABE?: UNA REVISIÓN DE LAS PRUEBAS DOCUMENTALES
}

\author{
POR \\ Carolina CARL \\ Doctora en Historia Medieval por la Universidad de St. Andrews, Escocia
}

\begin{abstract}
RESUMEN
El episcopado de Munio, obispo de Calahorra (1066-1080) coincidió con la supresión en la iglesia castellana del rito mozárabe, y su sustitución por la liturgia romana. Durante siglos, historiadores de la iglesia española han coincidido en poner este obispo al frente de una abierta defensa eclesiástica del antiguo rito peninsular. No obstante, un análisis detallado de los documentos del siglo XI y XII en que se basa esta tradición, revela que no tiene fundamento alguno, y nos obliga a identificar su fuente principal como una pieza de desinformación premeditada. Por otro lado, las circunstancias de la creación de esta fuente tienen interesantes implicaciones que permiten sugerir nuevas asociaciones vinculando a Munio de Calahorra con la defensa eclesiástica del rito mozárabe.
\end{abstract}

PALABRAS CLAVE: Castilla, Política eclesiástica, Rito mozárabe, Plena Edad Media, Munio obispo de Calahorra, San Millán de la Cogolla.

\section{MUNIO, BISHOP OF CALAHORRA, (1066-1080): DEFENDER OF THE MOZARABIC RITE? REVIEW OF THE DOCUMENTARY TEST}

\begin{abstract}
The episcopate of Munio, Bishop of Calahorra (1066-1080) coincided with the suppression within the Castilian church of the indigenous Mozarabic rite, and its substitution with the Roman liturgy. For centuries, historians of the Spanish church have upheld the tradition, based on the evidence of eleventh- and twelfth-century
\end{abstract}


sources, that Munio occupied a position at the forefront of a powerful Castilian clerical defence of the Mozarabic rite. However, careful analysis of the documentary evidence reveals this tradition to be a fallacy, and the source from which it principally sprung to constitute a deliberate exercise in misinformation. On the other hand, the circumstances that surrounded the fabrication, towards the beginning of the twelfth century, of the story of Munio's defensive heroism have interesting implications that may reveal different ways in which Munio of Calahorra can be associated with a clerical resistance to the imposition of the Roman rite.

KEY WORDS: Castile, Ecclesiastical politics, Mozarabic liturgy, Central medieval period, Munio Bishop of Calahorra, San Millán de la Cogolla.

Recibido/Received 16 enero 2007

Aceptado/Accepted 4 marzo 2007

El episcopado de Munio, obispo de Calahorra entre 1066 y 1080, coincidió con un período muy turbulento tanto en lo que refiere a la historia de la iglesia peninsular, como a la de su propio obispado. En el primer caso, la políticamente delicada sustitución del rito mozárabe por el romano iba ganando terreno en los reinos cristianos de la Península Ibérica, impulsada por un pontificado reformador cada vez más potente y menos tolerante hacia la diversidad litúrgica y teológica ${ }^{1}$. Este proceso se experimentó de distintas maneras, y dentro de distintos marcos cronológicos, en los diferentes reinos cristianos de la península.

En Aragón, donde la dinastía reinante mantenía unos estrechos vínculos con Roma puestos de manifiesto por el rey Sancho Ramírez (1063-94) al poner su reino bajo la protección de la Santa Sede en 1068, la primera misa cantada conforme al rito romano fue celebrada en el monasterio de San Juan de la Peña el 22 de Marzo de 1071. Ya en la primavera de 1074 el papa Gregorio VII (10731185) felicitaba al rey aragonés por su colaboración ${ }^{2}$. En el reino de Navarra, por contra, nada indica que el rey Sancho IV, «el de Peñalén», (1054-76) favoreciese el cambio de rito en su territorio. De hecho, habría que esperar hasta su asesinato en junio de 1076, y la posterior división de su colapsado reino entre Aragón y León-Castilla, para observar los primeros indicios de introducción del rito romano en tierra navarra. Las iglesias pertenecientes a la parte nororiental del desaparecido reino de Navarra fueron incorporadas a la política eclesiástica

1 J. F. Rivera Recio, 'Relaciones de la sede apostólica con los distintos reinos hispanos', en: R. García Villoslada, (ed.), Historia de la Iglesia en España, dirigida por Ricardo García Villoslada, Madrid, 1982, t. II, $1^{\text {a }}$ parte, pp. 257-85; A. UBIETO ARTETA, 'La introducción del rito romano en Aragón y Navarra', en: Hispania Sacra I (1948), pp. 299-324; P. DAvID, Études Historiques sur le Galice et le Portugal, du VIe au XIIIe siècle, Lisboa, 1947, pp. 391-430.

2 A.Olivier, 'La Iglesia en el reino de Aragón-Navarra', en: R. García Villoslada, (ed.), Historia de la Iglesia en España, dirigida por Ricardo García Villoslada, Madrid, 1982, t. II, 1a parte, p. 244; Ubieto, La introducción, pp. 308-11; Mansilla Reoyo, D. (ed.), La documentación pontifícia hasta Inocencio III (965-1216), Roma, 1955, 9.

Hispania Sacra, LX

122, julio-diciembre 2008, 685-701, ISSN: 0018-215-X 
de Sancho Ramírez de Aragón, y las de la Rioja, Álava y parte de Vizcaya y Guipúzcoa siguieron el camino marcado por la iglesia castellano-leonesa, que vamos a exponer brevemente a continuación ${ }^{3}$.

Bajo Alfonso VI (1072-1109) la sustitución del rito mozárabe por el romano en León-Castilla demostró ser un problema político mucho más complejo y polémico. El monarca pretendía defender sus ambiciones imperialistas frente a la amenaza de un pontificado que reclamaba la supremacía territorial sobre toda Iberia. De allí surgió su estrecha alianza con Cluny para desarrollar una política eclesiástica diseñada para mantener el frágil equilibrio entre, por un lado, la defensa de su propia soberanía territorial y el control político de la administración de la iglesia castellano-leonesa, y por otro las exigencias de Roma. La lenta y calculada implementación del cambio de rito en León-Castilla, a pesar de una aparentemente marcada resistencia eclesiástica, fue una de las concesiones a Roma en que se basaba esta política.

El primer indicio de que Alfonso VI estaba dispuesto a considerar la supresión del rito mozárabe en su reino se dio en 1074. Una delegación de obispos castellano-leoneses fue enviada al sínodo cuaresmal celebrado en Roma por Gregorio VII, el papa que con más fuerza reclamaba la supremacía de Roma. Tras un período de duda y crisis política doméstica desatada por este asunto, acompañada de una fuerte presión ejercida sobre el monarca leonés por parte del pontificado, la liturgia romana fue adoptada definitivamente por la iglesia castellano-leonesa en el Concilio de Burgos, celebrado durante la primavera de $1080^{4}$.

El obispado de Calahorra pasaba también por una fase insegura durante estos años. Entre 1066 y 1080 la sede de Calahorra y su obispo Munio se encontraban en pleno declive, iniciado incluso antes de la absorción por León-Castilla. Calahorra dejó definitivamente atrás la «época dorada» que había conocido durante el reinado de García III (1035-1054). Fue entonces la institución eclesiástica más destacada de una Navarra que estaba en el punto álgido de su proyección política y territorial hacia el suroeste 5 . Bajo Munio, el obispado riojano pasó a ser solo un representante más de la franja más vulnerable y periférica de la defensiva Navarra de Sancho IV6. Es más: el obispo de Calahorra pasó de ser el principal beneficia-

3 UBIETO, La introducción, pp. 304-8 y 318-22.

4 David, Études, pp. 391-430; J.M. MíngueZ, Alfonso VI: Poder, expansión y reorganización interior, Hondarribia, 2000, pp. 211-28; Serrano, L., El Obispado de Burgos y Castilla primitiva desde el siglo V al XIII, vol.I, pp. 287-321; J. FACI, 'La reforma gregoriana en Castilla y León’ en : R. García Villoslada, (ed.)., Historia de la Iglesia en España, dirigida por Ricardo García Villoslada, Madrid, 1982, t. II, 1a parte, pp. 262-75.

5 C. CARL, 'The coming-of-age of a northern Iberian frontier bishopric: Calahorra, 1045-1190', (Tesis doctoral inédita), University of St. Andrews, 2005, pp. 17-49.

${ }^{6}$ MinguÉz, Alfonso VI, pp. 62-3; J. Ma . LACARra, Historia del Reino de Navarra en la Edad Media, Caja de Ahorros de Navarra, 1975, pp. 121-5. 
rio del patronato regio navarro, con García III, a convertirse en mero confirmante de las numerosas e importantes donaciones hechas por Sancho IV al monasterio de San Millán de la Cogolla. Un claro reflejo de que el obispado de Calahorra ni siquiera representaba la principal línea de política eclesiástica de la Rioja navarra ya durante la primera década del episcopado de Munio ${ }^{7}$.

Quizá por haber sido una pieza clave en la identidad política navarra desde su refundación en 1045, el declive de Calahorra, tras del asesinato de Sancho IV en 1076, entró en una segunda fase, más profunda pues la anexión de su territorio por Alfonso VI de León-Castilla supuso la marginalización de su obispo y el desmantelamiento de la estructura territorial del obispado ${ }^{8}$. La mejor expresión de esta política es la transferencia a Cluny de la iglesia de Santa María la Real de Nájera, fundada y dotada entre 1049 y 1052 por García III de Navarra como sede y principal fuente de ingresos para el recién restaurado obispado de Calahorra 9 .

Este agravamiento de su decadencia durante el episcopado de Munio queda patente en el clamoroso silencio documental sobre el obispado de Calahorra, solo roto en cuatro ocasiones entre 1076 y la muerte de Munio en $1080^{10}$.

Ante esta situación, la figura de Munio parecería abocada al desprestigio si no fuera porque una larga serie de historiadores -aparentemente motivados más por patriotismo que por impulsos puramente críticos- coincidieron en ponerle al frente de una heroica defensa eclesiástica del antiguo rito peninsular en el momento de sustitución del rito mozárabe por el romano. El principal fundamento de esta opinión es un episodio narrativo cuya existencia histórica rara vez se ha cuestionado. Me propongo revisar ese material y otros relacionados con él y las opiniones que derivan de ellos.

\section{El supuesto Viaje De Munio a Roma}

Munio aparece como defensor del rito mozárabe en un texto inserto tardíamente en el bien conocido Codex Emilianense compilado en San Millán de la Cogolla durante los años 70 del siglo diez, actualmente guardado en la Biblioteca de El Escorial (I d. I, fol.395 v.) ${ }^{11}$. En él se relata cómo los obispos hispanos, «vehementer

${ }^{7}$ A. Ubieto Arteta (ed.), Cartulario de San Millán de la Cogolla (759-1076), Valencia, 1976, 3445, 357, 360, 362, 368, 377, 381, 384, 398-9, 401, 407-8, 414, 418, 421-2, 424-5, y 432; G. MARTíNEZ DíEZ, 'El monasterio de San Millán y sus monasterios filiales: Documentación emilianense y diplomas apócrifos’, en: Brocar 21 (1997), pp. 46-7; Ubieto, La introducción, pp. 304-6.

${ }^{8}$ Mínguez, Alfonso VI, pp. 62-3; Carl, Coming-of-age, pp. 66-9.

${ }^{9}$ Ibid., pp. 20-5 y 68-74.

10 Ibid., p. 67.

${ }^{11}$ M. DíAZ y Díaz, Libros y librerías en la Rioja altomedieval, Instituto de Estudios Riojanos, Logroño, 1991, pp. 155-7. El texto está reproducido en el Apéndice 1 de este artículo.

Hispania Sacra, LX

122, julio-diciembre 2008, 685-701, ISSN: 0018-215-X 
Iratí» por los intentos, primero del legado pontificio Hugo Cándido, y después de otros cardenales romanos, de introducir el rito romano en sus tierras, escogieron a tres obispos, Munio de Calahorra, Jimeno de Oca y Fortún de Álava. Los mandaron a la curia pontificia con un liber ordinum, un liber orationum, un liber antiphonarum, y un liber missarum, a fin de someter estos textos ejemplares de la liturgia mozárabe al juicio del papa Alejandro II (1061-1073). Los textos fueron examinados por el papa y su corte durante un período de diecinueve días, antes de ser declarados completamente libres de toda heterodoxia. Los obispos hispanos, habiendo recibido la bendición del papa, volvieron a casa con mucha alegría.

La veracidad de esta decisiva y unida defensa del rito autóctono por parte del episcopado hispano frente al agresivo intento romano de suprimirlo, fue aceptada y reiterada, tal como fue formulada en el escritorio emilianense, por una larga serie de historiadores peninsulares, que incluye entre otros a Mariana (1536-1624), Baronio (1538-1607), Moret (1684), Flórez (1702-1773), Tejada y Ramiro (1859), el historiador del obispado de Burgos, Luciano Serrano (1935), Pérez de Urbel y González y Ruiz Zorrilla, y el historiador de Navarra, Lacarra (1976), quienes a menudo se inclinaban a defender el viejo rito autóctono por razones patrióticas ${ }^{12}$.

Curiosamente, este episodio ha recibido también el respaldo de algunos historiadores del siglo pasado, como Férotin y Kehr, cuya posición como observadores extra-peninsulares les podía haber conducido a un análisis más crítico de un relato tan tentador para la tradicionalista historiografía eclesiástica ibérica ${ }^{13}$. De hecho, habría que esperar esta mirada crítica algo más de ocho siglos. Fue proporcionada por el historiador francés Pierre David en sus «Estudios históricos sobre Galicia y Portugal, siglos VI a XII», publicados en 1947. Sus argumentos para rechazar la veracidad del relato incluido en el manuscrito emilianense son los siguientes:

En primer lugar, advierte que no hay ninguna otra prueba documental, ni de procedencia romana, ni de procedencia ibérica, que corrobore esta historia. Califica de «absurda» la idea de que el papa Alexandro II podría haber dado por

\footnotetext{
12 J de Mariana, De Rebus Hispanicis, 1608, 2 tomos, t. I, IX, cap. 5; C. Baronius, Annalium Ecclesiasticorum, 1740, ad annum 1064, 42; Herreros Lopetegui, S. (ed.), J. DE Moret, Anales del Reino de Navarra, Tolosa, 1890-1910, 4 tomos, t. 3, pp. 9-16; E. Flórez, España Sagrada, t. III, Madrid, 1754, pp. 272-87 \& appéndice III, no. III; Tejada y J. RAMIRO, Colección de cánones y de todos los concilios de la Iglesia española, Madrid, 1859, t. III, pp. 172-5; L. SERRANO, El Obispado de Burgos y Castilla primitiva desde el siglo V al XIII, Madrid, 1935, t. I, pp. 267-8; J. PÉrEZ DE UrBEL \& G. GONZÁLEZ y RuIZ ZoRrILla, Liber Commicus, Madrid, 1955, t. I, pp. 144-5; Lacarra, Reino de Navarra, p. 186.

${ }^{13}$ D. M. FÉrotin, 'Le Liber Ordinum en usage dans l'Eglise wisigothique et mozarabe d'Espagne du cinquème au onzième siècle', en: Monumenta Ecclesiae liturgica, t. V, Paris, 1907, p. 19; P. KEHR, 'Cómo y cuando de hizo Aragón feudatario de la Santa Sede', en: Estudios de la Edad Media de la Corona de Aragón, Zaragoza, 1945, t. I, pp. 295-6.
} 
bueno en los últimos años de su pontificado textos de un rito eclesiástico que anteriormente había condenado como «irregular, aberrante y herético». De la supuesta cronología de este episodio hablaremos más adelante.

David expresó sus dudas en cuanto a la posibilidad de que hubiera participado en el supuesto viaje el obispo Jimeno de Oca (Burgos), bien conocido como aliado clave de Roma en lo referente al cambio de rito en León-Castilla.

Para explicar la existencia de este relato, sugiere que fue incorporado al Codex Emilianensis entre 1070 y 1090 por un monje del monasterio para fortalecer la resistencia eclesiástica peninsular a la imposición del rito romano a través de la propaganda y de la desinformación. En apoyo a esta teoría, cita una carta enviada al obispo Jimeno de Burgos por Gregorio VII en 1076. El papa denunciaba intentos parecidos de distorsionar los pronunciamientos de Roma: «Quod autem filii mortis dicunt se a nobis litteras accepisse sciatis per omnia falsum esse» ${ }^{14}$.

A pesar de la aparente solidez de estos argumentos, algunos historiadores los rechazan, alegando la dificultad que conllevaba falsificar con tanta precisión un relato como este, en el que coinciden tantos y tan distintos personajes y circunstancias. Se tiende así a creer que, si se tratase de una ficción, hubiera debido ser redactado mucho después y, en ese caso, no hubiera sido fácil alcanzar ese grado de precisión factual ${ }^{15}$.

Eliseo Saínz Ripa, autor de la única monografía que cubre la historia del obispado de Calahorra en el siglo XI y el más ardiente defensor de la reputación patriótica de «su» obispo Munio, aduce en refuerzo de la veracidad del episodio otras evidencias documentales que conviene analizar

\section{LA SUPUESTA DEPOSICIÓN DE MUNIO}

En palabras de Sáinz Ripa, «... [El Cardenal Giraldo, Legado del Papa Gregorio VII (1073-1085)] celebró un concilio en que fue depuesto y excomulgado el obispo de Calahorra Munio, a quien se acusaba de ordenación simoníaca. El historiador se pregunta si esta condena no sería una razón marginal para doblegar el ánimo irreducible de los obispos hispanos opuestos al cambio de rito. Munio marchó a Roma con los obispos aragoneses y castellano-leoneses para asistir al sínodo cuaresmal de 1074. El calagurritano fue absuelto, pero bajo la promesa formal de que habría de aceptar en su territorio el oficio romano» ${ }^{16}$.

\footnotetext{
${ }^{14}$ DAVID, Études, pp. 391-5.

15 Ubieto, La introducción, p. 9; E. SAINZ RIPA, Sedes episcopales de la Rioja, Logroño, 1994, t. I, p. 254; Rivera, Las relaciones, pp. 260 y 277.

16 Ibid., p. 255.

Hispania Sacra, LX

122, julio-diciembre 2008, 685-701, ISSN: 0018-215-X
} 
Si en relación con el viaje a Roma hay consenso, en cuanto a la interpretación histórica de este nuevo episodio, existe una confusa variedad de propuestas. La identificación de su protagonista como el obispo Munio de Calahorra la comparte Sainz Ripa con Rivera Recio y Pérez de Urbel y González y Ruiz Zorrilla ${ }^{17}$. Tanto Tejada y Ramiro como Serrano y, más recientemente, Joseph O'Callaghan, identificaron al protagonista de este segundo episodio, como un obispo Munio de Castilla la Vieja. Sin embargo, están de acuerdo con Sáinz Ripa y Rivera Recio cuando consideran la absolución pontificia del excomulgado obispo como consecuencia directa de su promesa de apoyar el cambio de rito ${ }^{18}$.

La versión más reciente de este episodio la proporciona José María Mínguez en su monografía sobre el reinado de Alfonso VI. Según él, fue el rey de LeónCastilla quien depuso al obispo Munio de Oca-Burgos, el cual, fracasada la recomendación conseguida de Roma para ser reinstituido en su cargo, se habría recluido en el monasterio de Cardeña ${ }^{19}$. En cambio, Pierre David había supuesto que este episodio tenía por protagonista al obispo Munio de Castilla la Vieja, y que su absolución por el papa se hizo a condición de que renunciase a su querella con Jimeno, obispo de Burgos, y no a cambio de la promesa de apoyar la introducción del rito romano. No obstante, esta interpretación, a mi parecer correcta, no la apoya el historiador francés con ningún argumento ${ }^{20}$. Hay que volver, pues, a analizar las fuentes y el contexto histórico de este segundo episodio de la historia de Munio como defensor del rito mozárabe para clarificar este confuso asunto.

No hay ningún texto narrativo que relate los acontecimientos descritos desde una posición de cercanía cronológica. Las diversas opiniones historiográficas sobre este episodio derivan de la interpretación de dos cartas escritas por Gregorio VII en 107421. La primera, del 20 de marzo de 1074, dirigida a los reyes Alfonso VI de León-Castilla y Sancho IV de Navarra, contenía una ratificación pontificia de la deposición y excomunión impuestas previamente a un obispo llamado Munio por el legado Giraldo. En la segunda, del 9 de mayo del mismo año, dirigida sólo al rey de León-Castilla, se informaba de la absolución del obispo y de su promesa de implantar en su territorio el rito romano.

17 J. F. RIVERA RECIO, 'La supresión del rito mozárabe y la introducción del romano’, en: Historia de la Iglesia en España, dirigida por Ricardo García Villoslada, Madrid, 1982, t. II, 1a parte, p. 279; PÉREZ de URBel \& GonZÁlez y RuIz ZorRILla, Liber Commicus, t. I, pp. 144-5.

18 Tejada y Ramiro, Colección, v.III, p. 185; Serrano, Obispado, pp. 290-4; J. F. O’CALLAGHan, 'The Integration of Christian Spain into Europe: The Role of Alfonso VI of León-Castile', en: B. Reilly (ed.), Santiago, St. Denis, and St. Peter: The Reception of the Roman Liturgy in León-Castile in 1080, Nueva York, 1985, pp. 105-6.

19 MíngueZ, Alfonso VI, p. 226.

20 DAVID, Études, p. 397.

${ }^{21}$ La reproducimos como fueron publicadas por Demetrio Mansilla Reoyo, en los apéndices 2a y $2 \mathrm{~b}$. 
La identificación de Munio obispo de Calahorra como protagonista episcopal de estas dos cartas es problemática por varias razones. La más obvia tiene que ver con su cronología. La primera de estas dos cartas fue escrita justo después del sínodo cuaresmal que Gregorio VII celebró entre el 9 y el 15 de marzo de 1074. La segunda, fechada en 9 de mayo, expresa de manera explícita que el obispo Munio había asistido al sínodo y había apelado ante la curia pontificia contra la sentencia dictada por el legado. Esta apelación la tenemos que fechar entre el 20 de marzo, día en que el papa ratificó la excomunión de Munio, y el 9 de mayo, día en que comunicaba su absolución. Esto significa que el obispo Munio debería haber permanecido en Roma por lo menos hasta principios de abril, cosa incongruente con el testimonio de una carta fechada en 12 de abril de 1074 que recoge la suscripción de una donación al monasterio de San Millán de la Cogolla por Munio, obispo de Calahorra ${ }^{22}$.

La segunda razón concierne a la identificación en estas cartas pontificias de Munio como un obispo de Castilla la Vieja con sede en Sasamón, a unos 30 kilómetros al oeste de Burgos. Aunque sería tentador tomar este dato como prueba de la continuación del poder del obispo de Calahorra en los territorios de Castilla la Vieja cuya administración le había sido proporcionada durante el reinado de García III de Navarra, tenemos que descartar esta idea. Primero, porque la reasimilación política de estos territorios por parte de Castilla ya había sido completada hacia 106723; segundo, porque no hay ninguna otra prueba que vincule al obispo o obispado de Calahorra con estos territorios durante el episcopado de Munio ${ }^{24}$; y tercero, porque el testimonio de un documento, escrito en San Millán de la Cogolla en 1067, registra la asistencia tanto de «Munionem Calagurritanum pontificiem» como de «Munionem Vetule Castelle presulem» al concilio legatino de Llantada de aquel año. Deja así clara la coexistencia en este período de dos obispos vecinos llamados Munio 25 .

Vale la pena preguntar por qué razón Munio de Calahorra, regente de un obispado perteneciente al reino de Navarra hasta junio de 1076, se habría unido a una delegación de obispos castellano-leoneses y aragoneses para acudir a Roma en la primavera de 1074. Del mismo modo, hay que preguntar por qué Gregorio VII habría informado exclusivamente a Alfonso VI, rey de León-Cas-

\footnotetext{
22 Ubieto, Cartulario de San Millán, 415; Carl, Coming-of-Age, p. 53. Las listas de los confirmantes de las donaciones privadas hechas al monasterio de San Millán durante este período variaban mucho según la fecha y lugar de su redacción, y la identidad del donante. Así se puede asociar la apariencia del obispo Munio en la lista de los confirmantes de esta donación con su presencia física en el acto.

${ }^{23}$ MíngueZ, Alfonso VI, pp. 61-2.

${ }^{24}$ CARL, Coming-of-Age, p. 64.

${ }^{25}$ Ubieto, Cartulario de San Millán, 361.
}

Hispania Sacra, LX

122, julio-diciembre 2008, 685-701, ISSN: 0018-215-X 
tilla, de la absolución del obispo Munio si éste era el obispo navarro de Calahorra y no el obispo castellano de Castilla Vieja.

Nuestro rechazo a la identificación del «obispo Munio» mencionado en estas cartas como Munio de Calahorra se refuerza por un análisis mas detallado de sus contenidos. Estos revelan que el principal problema que había enfrentado con la sede pontificia al obispo Munio, «qui super Symeonem venerabilem fratem nostrum Ocensem episcopatum ordinatus erat» (app. 2a), había sido su oposición a la absorción de su obispado por el de Burgos a consecuencia del proyecto, apoyado por Roma, de reubicar el obispado de Oca en Burgos ${ }^{26}$.

Queda claro, pues, que Munio, obispo de Calahorra, no tenía nada que ver con este supuesto segundo viaje a Roma. Es más, si seguimos examinando las fuentes de este segundo episodio, veremos cómo la absolución de su protagonista por el papa debe ser disociada de la famosa promesa acerca del cambio de rito. De hecho, la absolución del obispo Munio esta ligada en la segunda de estas cartas no a su sumisión en cuanto al cambio de rito, sino a su renuncia a «rationem earum rerum quibus eum appellavimus, sicut dignam erat» (app. 2b). Además, cuando Gregorio VII menciona la promesa episcopal de observar el rito romano, precisa que ésta se realizó conjuntamente con el resto de los obispos hispanos en el contexto del sínodo cuaresmal de 1074: «Romanum ordinem in divinis officiis, sicut ceteri Hyspani episcopi, qui synodo interfuerunt, se celebraturum et, ut melius poterit observaturum promisit» (app. 2b). Tanto el hecho que este sínodo fuese cerrado cinco días antes de la ratificación pontificia de la excomunión de Munio el 20 de marzo, como que esta promesa había sido hecha de forma generalizada por todos los obispos hispanos que habían asistido al sínodo cuaresmal, y, por tanto, no solo por el obispo Munio, demuestran que no había una relación directa causa-efecto entre la promesa del obispo de apoyar el cambio de rito y su absolución por del papa.

Podemos concluir entonces que el obispo Munio, que viaja a Roma en 1074, no es el de Calahorra, sino un efímero obispo de Castilla la Vieja, enfrentado principalmente con la sede pontificia no por su resistencia a la inminente supresión del rito mozárabe, sino por su rechazo a la asimilación de su obispado por el de Burgos. Si consiguió ser absuelto por el papa, fue debido a la renuncia a sus pretensiones de mantener sus aspiraciones sobre territorios que reclamaba el obispado de Oca-Burgos, y no a raíz de una promesa colectiva hecha junto a numerosos obispos hispanos de apoyar la introducción del rito romano en la iglesia peninsular.

26 Para una discusión de este proceso, ver: SERRANo, Obispado de Burgos, pp. 263-321. 


\section{POSIBLE SIGNIFICADO DE UN EPISODIO FICTICIO}

Aunque nos hayamos visto forzados a rechazar totalmente la veracidad de los dos episodios en que se fundaba la reputación del obispo Munio de Calahorra como defensor del rito mozárabe, esto no significa que las fuentes en que se han basado estos episodios no puedan verter claridad sobre este tema de manera más indirecta. Este es especialmente el caso del relato emilianense, fuente de nuestro «episodio uno», que parte, no de una interpretación histórica tardía, sino de un texto bastante próximo en el tiempo con el contexto histórico a que se refiere.

Para discutir la relevancia histórica del relato emilianense, es importante plantear ciertas preguntas acerca de su redacción: ¿Cuándo, y dónde, fue escrito? ¿En qué contextos específicos, cronológicos, políticos, eclesiásticos, regionales, sitúa este texto los hechos que narra? ¿Por quién fue escrito, para qué público, y con qué motivos? Aunque queda mucho por matizar, las respuestas, o medias respuestas, que podemos proponer pueden servir como base para una hipótesis sobre el significado del texto.

Se sabe que el texto, que recoge nuestro «episodio uno», se insertó con posterioridad en un códice compilado en el monasterio riojano de San Millán de la Cogolla en la segunda mitad del siglo X. No obstante, la fecha entre 1070 y 1090 David no la justifica con ningún argumento ${ }^{27}$. Para una aproximación a la fecha de su redacción vale la pena establecer primero un terminus post quem, definido por el contexto histórico en que este ficticio episodio fue colocado por su autor.

El relato no precisa la supuesta fecha de ida de los tres obispos a Roma. No obstante, la exactitud con que su autor identifica los protagonistas y el contexto de su inventada historia justifica el intento de precisar la fecha de los hechos ficticios que narra en relación a otros hechos históricos, que incorpora el texto. En él menciona un concilio donde los obispos hispanos presentaron los textos litúrgicos. Eso ha llevado tradicionalmente a aceptar 1064, año en que se celebró el Concilio Pontificio de Mantua, como la fecha del pretendido viaje episcopal $^{28}$.

Los problemas asociados a esta fecha son numerosos. Consideremos primero los ya identificados por Pierre David, que rechazó el Concilio de Mantua como contexto de este primer episodio porque el mismo relato emilianense menciona al viaje de los obispos como una reacción a la legación de Hugo Cándido a la Península Ibérica, no anterior a 1065. Añadía David que el texto menciona de manera explícita cómo los libros fueron presentados en Roma, sin

${ }^{27}$ DAVID, Études, p. 391.

${ }^{28}$ DAVID, Études, p. 393.

Hispania Sacra, LX

122, julio-diciembre 2008, 685-701, ISSN: 0018-215-X 
mencionar en ningún momento Mantua. A continuación, David argumentaba que el «consilium» mencionado por el texto podría referirse a cualquiera de los sínodos cuaresmales de Alejandro II, así como a las reuniones regularmente celebradas por el papa en el consistorio. Añadía que una fecha anterior a 1067 resultaría inverosímil dado que el obispado de Oca-Burgos, sede de uno de los tres obispos protagonistas del relato, no fue restaurado hasta aquel año. Así David apuntaba al periodo comprendido entre 1067 y la muerte de Alejandro II en 1073 como el más probable contexto cronológico de este episodio ${ }^{29}$. Esta ventana cronológica se puede precisar más teniendo en cuenta que la primera aparición en la documentación del obispo Fortún de Álava lleva fecha del año $1070^{30}$.

Habiendo identificado este terminus post quem de 1070-1073 para la redacción del texto de nuestro «episodio uno», definido por el contexto histórico de su narración, podemos deducir una posible razón, que está implícita en el propio texto, para retrasar algo más la fecha de su inserción en el Codex Emilianensis. Para verla, es necesario insistir en la escasa credibilidad atribuible al episodio del viaje de los tres obispos para un público directamente contemporáneo al contexto en que se sitúa. ¿Cómo no iban a saber sus coetáneos directos que estos tres obispos nunca habían partido juntos hacía Roma? ¿Cómo hacerles creer que Jimeno, bien conocido como uno de los principales aliados de Roma en el tema del cambio de rito, participó en la defensa de la liturgia mozárabe $^{31}$ ? Y ¿cómo hacer creíble, en un contexto eclesiástico dominado por un ataque pontificio intenso y prolongado contra el predominio del rito autóctono ibérico, la defensa del rito mozárabe atribuida a Alejandro II por el «relato emilianense», que describe cómo el papa amenazó con un entredicho a cualquiera que presumiera de perturbar, condenar, o modificar de algún modo la liturgia hispana (app.1)? Parece claro que el público a quien iba dirigido este relato debería estar a una distancia temporal de por lo menos una generación respecto del episodio narrado.

Un análisis físico del propio texto y su relación con el códice en que se encuentra apoyan esta idea. Manuel Díaz y Díaz ha proporcionado un detallado estudio del Codex Emilianensis ${ }^{32}$. Identifica varias piezas «probablemente elaboradas también en el monasterio de San Millán» y añadidas al códice después de su compilación original, entre ellos el texto de nuestro «episodio uno». De ellas dice: «La letra en estos añadidos parece única, e incluso la pluma utilizada no es del tipo normal: hay vacilación en el ductus y cierta inseguridad en las

\footnotetext{
29 Ibid., pp. 393-4.

30 Ubieto (ed.), Cartulario de San Millán, 377.

31 Para el importante papel jugado por Jimeno de Burgos como promotor del cambio de rito, ver: Serrano, Obispado de Burgos, pp. 287-321.

32 DíAz y DíAz, Libros y librerías, pp. 155-62.
} 
abreviaturas. Todo justifica la adscripción a la era mencionada en el fol. 396v: era MCLXXVIII, año $1140 »^{33}$. La idea de esta unidad paleográfica del bloque de textos añadidos que incorpora nuestro «episodio uno» está apoyada por el hecho que los folios que lo componen claramente constituyen un cuaderno aparte dentro de lo que es el códice entero.

No obstante, la fecha que Díaz y Díaz atribuye a estos textos añadidos (1140) resulta de una lectura incorrecta de la fecha expresada en el fol. 396v.: $\mathrm{T}^{\mathrm{a}} \cdot \mathrm{C}^{\mathrm{a}}$. LXX $^{\mathrm{a}}$.VIII ${ }^{\mathrm{a}}$ (año 1140) en vez de la correcta $\mathrm{T}^{\mathrm{a}}$. ${ }^{\mathrm{a}}$. $\mathrm{XXX}^{\mathrm{a}}$.VIII ${ }^{\mathrm{a}}$ (año 1100). Esta fecha viene al final de una sección del cuaderno que contiene un registro de cartas pontificales, seguido de noticias de algunos concilios eclesiásticos, terminando con una referencia al concilio de Palencia de 1100, en el que estuvieron presentes los arzobispos Bernardo de Toledo y Geraldo de Braga, y los obispos Pedro de León y García de Burgos. Es a este encuentro al que se aplica la data de 1100, lo cual confirma lo erróneo de la data de Díaz y Díaz y que nuestro «episodio uno» formaba parte de un pequeño bloque de textos insertos en el Codex Emilianensis a inicios del siglo XII.

Ahora bien, un análisis detallado de los contenidos del relato emilianense, en relación con el contexto político, eclesiástico, y regional de donde surge, nos ofrece una interesante oportunidad de replantear esta asociación de Munio con la defensa del rito mozárabe. Primero, debemos considerar el énfasis navarro en el texto. Aunque dos de los tres obispos citados proceden del ámbito castellano, el párrafo final de la noticia -que podría ser una adición efectuada no mucho después de terminar de copiar la historia-identifica todos los manuscritos examinados como procedentes de monasterios navarros: Irache y Santa Gema, cerca de Estella y Albelda, en la Rioja, pero que pertenecían al ámbito navarro hasta 1076. Este énfasis navarro en un relato que celebra tan convencidamente la defensa del rito mozárabe encaja con lo que ya sabemos acerca del frontal rechazo, mostrado por la monarquía navarra, antes de su desaparición en 1076, a los intentos pontificios de introducción del rito romano en sus territorios. A esos intentos se refiere explícitamente la carta pontificia reproducida en el apéndice 2a).

También es interesante considerar el relato emilianense en relación con su procedencia mas regional. En este sentido, debemos subrayar que los tres obispos que protagonizan este episodio regían diócesis cuyos territorios, anteriormente navarros, habían sido arrebatados después por Castilla: en el caso de gran parte del obispado de Oca durante la década de los 60 del siglo XI, y en el de los de Calahorra y Álava, con la desaparición de Navarra en 1076. ${ }^{34}$ Este elenco concordaba, pues, con la posición geopolítica del monasterio de San Mi-

${ }_{33}$ Díaz y Díaz, Libros y librerías, pp. 155, nota 65.

${ }^{34}$ MíngueZ, Alfonso VI, pp. 62-4.

Hispania Sacra, LX

122, julio-diciembre 2008, 685-701, ISSN: 0018-215-X 
llán de la Cogolla, objeto de intensa disputa entre Navarra y Castilla desde los 60, y que después de 1076 se convertiría en la institución eclesiástica mas destacada y promocionada de una Rioja enfáticamente castellana ${ }^{35}$. Parece que el autor de este episodio quería no solamente fortalecer el binomio identidad navarra/resistencia al cambio de rito, sino también establecer un contraste entre los «buenos viejos tiempos» navarros, y un presente (c.1100), caracterizado por el dominio político castellano y las reformas eclesiásticas que conllevaba. Surge así la posibilidad de plantear una situación de conflicto dentro del propio monasterio de San Millán, teniendo a un lado al nostálgico autor del relato emilianense perteneciente a una conservadora facción anti-castellana, y por otro a otra facción, dominante, reformista, y de reciente implantación castellana.

De hecho, la pervivencia de una facción conservadora y opuesta al cambio de rito dentro de San Millán a principios del siglo XII parece muy posible si la consideramos como seguidora de una nostálgica tradición emilianense, documentada para los años 80 del siglo anterior. Esta voz disidente nos llega a través del Liber Commicus, un texto litúrgico mozárabe, copiado en el escritorio de San Millán durante las décadas 70 y 80 del siglo XI, y editado por Pérez de Urbel y González y Ruiz Zorrilla ${ }^{36}$. Su escribano era Pedro, abad de San Millán hasta 1067, en que cesó, me pregunto si de grado, para dedicar el resto de sus días, al menos hasta 1084, a trabajar en el escritorio del monasterio riojano ${ }^{37}$. Como si el hecho de copiar un texto litúrgico mozárabe por estas fechas no fuera muestra suficiente de la postura de Pedro respeto al cambio de rito, el escribano incluyó en la parte final de su obra un pequeño texto dedicado a defender en términos altamente emotivos la vieja liturgia autóctona ${ }^{38}$.

Para entender las conexiones que pueden haber existido entre una hipotética facción disidente dentro del monasterio de San Millán y el obispo de Calahorra, se debe considerar tanto la estrecha relación que existió entre los dos durante las primeras dos décadas posteriores a la refundación del obispado de Calahorra en 1045, como su rivalidad a partir de los últimos años de la década de los 60 del siglo XI. En este sentido es necesario recordar que Munio fue el primer obispo del restaurado obispado de Calahorra que no sumó el abadiato de San Millán a su título episcopal, asociación de poderes que también se reflejaba en el uso de San Millán como sede principal de los obispos de Calahorra hasta c. $1050^{39}$.

\footnotetext{
${ }^{35}$ Martínez DíEz, San Millán, pp. 9, 19, 33, 40-1 y 46-7; F. J. García Turza, 'El monasterio de San Millán de la Cogolla en la Alta Edad Media: Aproximación histórica’, en: Berceo 133 (1997), pp. 9-25.

36 Pérez de Urbel \& GonZÁlez y Ruiz Zorrilla, Liber Commicus, t. I \& II.

37 Pérez de Urbel \& GonzÁlez y Ruiz Zorrilla, Liber Commicus, t. I, p. 147.

38 Pérez Urbel \& GonZÁlez y Ruiz Zorrilla, Liber Commicus, t. II, p. 715.

${ }^{39}$ CARL, Coming-of-Age, pp. 31-6 y 53.
} 
Igualmente relevante es la sustitución al frente del monasterio riojano a poco tiempo del comienzo del episcopado de Munio. Fue relevado el abad Pedro, último de una serie que había regido a San Millán bajo la autoridad directa de los obispos de Calahorra, y autor de la «defensa del rito mozárabe» arriba mencionada. Es más, San Millán consiguió independizarse del dominio fiscal y jurisdiccional del obispo de Calahorra de manera muy importante a través de concesiones obtenidas en el Concilio de Llantada en 1067. Fue elevado por Alfonso VI al primer plano eclesiástico de la Rioja castellana, situación que contrasta fuertemente con la agresión regia sufrida por Calahorra después de $1076^{40}$.

En este contexto, se puede plantear una posible ruptura dentro de San Millán alrededor de 1066/1067 que, en un principio, tenía que ver con la «castellanización» del monasterio y la afirmación de su independencia de los obispos de Calahorra más que la polémica sobre la sustitución del rito mozárabe, que se vendría a asociar con una fuerte influencia castellana años más tarde.

1. Aunque por el momento nos tengamos que limitar al plano puramente conjetural, es interesante apoyarnos en este contexto de cambiantes relaciones entre el obispado y San Millán durante la última mitad del siglo XI para proponer dos hipótesis. Una, que la inclusión por parte de un monje emilianense en 1100 del obispo de Calahorra, y no de un abad de San Millán, como protagonista riojano de una ficticia defensa del rito mozárabe en 1070-1073, podría reflejar una identificación real que había existido una generación atrás entre Munio, un obispo de marcada identidad política navarra, y una facción minoritaria anticastellana dentro del cenobio de San Millán, quizás focalizada por la figura del ex-abad Pedro. Dos, que esta inclusión representaba un llamamiento al entonces obispo de Calahorra, Pedro (1089-1108) a seguir el «buen ejemplo» de su antecesor, prescindiendo que tuviera una base histórica, resistiendo ante la «romanización»y «castellanización» de la iglesia en su diócesis. Esto, a su vez, sugiere que la tensión entre castellanos y navarros, que probablemente se dio en el momento de la incorporación a Castilla, no había remitido una generación después. Seguía proporcionando el contexto para una reivindicación de elementos clave de la identidad política navarra, en este caso a través de una falsificación de hechos del pasado, creíble por la mayor distancia en el tiempo.

De esta manera parece finalmente posible rescatar la idea de una relación entre el obispo Munio de Calahorra y la defensa del rito mozárabe, no como heroico protagonista de dos llamativos viajes a Roma, sino como inspiración, activa o meramente simbólica, en vida o «en espíritu» veinte años después de su muerte, de una facción disidente en el seno del monasterio de San Millán que se

${ }^{40}$ Ubieto (ed.), Cartulario de San Millán, 361.

Hispania Sacra, LX

122, julio-diciembre 2008, 685-701, ISSN: 0018-215-X 
oponía al cambio de rito y a la influencia castellana. Para profundizar en esta hipótesis, sería conveniente un estudio mas detallado de los contenidos y paleografía del códice en que se encuentra el relato emilianense; conocer la dinámica política dentro del cenobio riojano durante las últimas décadas del siglo once y primeras del doce y la relación entre el obispado de Calahorra y el monasterio de San Millán durante este periodo. Estas tareas quedan, por el momento, como propuestas para un futuro trabajo.

APPENDICE 1: Párrafo 3 del Codex Emilianense guardado en la Biblioteca de El Escorial, I d. I, fol. 397 v., tal como esta reproducido en Flórez. E., España Sagrada: Tomo III, Theatro Geográphico Histórico de la Iglesia de España, Madrid, 1754, Apéndice III, Número III (p.389).

Ergo hac auctoritate masit ratum \& laudabile officium Ispane eclesie usque ad tempora domini alexandri secundi pape. Quo alexandro papa sedem apostolicam era .....[1099] obtinente, \& domno ferdinando rege Ispane regione imperante quidam cardinalis hugo candidus vocatus a prefato papa alexandro missus Ispaniam venit: officium eclesie ejus a supra nominato jhoane papa laudatum et roboratum evertere voluit: sed apostolica auctoritate munitum \& confirmatum inveniens intactum ut invenit reliquit. cui cardinali succedentes quidam cardinales alii hoc idem facere laboraverunt, sed nullo modo facere potuerunt. Pro qua re Ispaniarum episcopi vehementer irati consilio initio tres episcopes romam miserunt, scilicet, munnionem calagurritane, \& eximinum auccensum \& fortunem alabensem. hi ergo cum libris officiorum Ispanarum eclesiarum fe domino pape Alexandro presentarunt libros quos portaverunt obtulerunt, id est, librum ordinum $\&$ librum missarum $\&$ librum orationum $\&$ librum antifonarum. Quos libros domnus papa \& omne concilium suscipiens diligenter prescutantes $\&$ sagaci studio perquirentes, bene catholicos \& omni heretica pravitate mundos invenerunt \& nequis amplius officium Ispane eclesie inquietaret vel damnaret vel mutare presumeret apostolica auctoritate proibuerunt \& etiam interdixerunt. \& data benedictione super prefhatos epõs. eos cum letitia, ad propria redierunt.

Ex libris quos portaverunt ad romam unum fuit ordinum maioris alballdensis cenobii ubi continetur baptismum \& sepultura \& tenuit papa alexandrus \& fuit bene laudatum. alium librum orationum de monasterio iraze $\&$ tenuit abba sancti benedicti \& fuit bene laudatum. \& librum missale fuit de sancta gemma $\&$ librum antifonarum de Iraze. ita diviserunt decem \& novem diebus tenuerunt $\&$ cuncti laudaverunt.

APPENDICE 2a: Bula del papa Gregorio VII fechada el 19 de Marzo de 1074, y dirigida a los reyes Alfonso VI de León-Castilla y Sancho IV de Navarra, tal 
como esta reproducida en: Mansilla Reoyo, D. (ed.), La documentación pontificia hasta Inocencio III (965-1216), Roma, 1955, no.8:

\section{A[lfonso] et S[ancio] regibus Hyspanie}

Gregorius episcopus, servus servorum Dei Alfonso et Sanctio regibus Hyspanie a paribus, et episcopis in dicione sua constitutis, salutem et apostolicam benedictionem.

Cum beatus apostolus Paulus Hyspaniam se adiisse significet ac postea septem episcopus ab urbe Roma ad instruendos Hyspanie populos a PETRO et PAULO apostolis directos fuisse, qui destructa idolatria christianitatem fundaverunt, religionem plantaverunt, ordinem et officium in divinis cultibus agendis ostenderunt, et sanguine suo ecclesias dedicaverunt, vestra diligentia non ignoret, quantam concordiam cum Romana urbe Hyspania in religione et ordine divini officii habuisset, satis patet. Sed postquam vesania Priscillianistarum diu pollutum, et perfidia Arrianorum depravatum, et a Romano ritu separatum, irruentibus prius Gothis, ac demum invadentibus Saracenis, regnum Hyspanie fuit, non solum religio est diminuta, verum etiam mundane sunt opes labefacte. Quapropter ut filios karissimos vos adhortor et moneo, ut vos sicut bone soboles, etsi post diuturnas scissuras, demum tamen ut matrem revera vestram Romanam ecclesiam recognoscatis, in quo et nos fratres reperiatis, Romane ecclesie ordinem et officium recipiatis, non Toletane, vel cuiuslibet alie, sed istius, que a PETRO et PAULO supra firmam petram per Christum fundata est et sanguine consecrata, cui porte inferni, id est lingue hereticorum, unquam prevalere potuerunt, sicut cetera regna Occidentis et Septemtrionis teneatis. Unde enim non dubitatis vos suscepisse religionis exordium, restat etiam, ut inde recipiatis in ecclesiastico ordine divinum officium; quod Innocentii pape ad Egubinum directa episcopum vos docet epistola, quod Ormisde ad Hispalensem missa decreta insinuant, quod Toletanum et Bragarense demonstrant concilia, quod etiam episcopi vestri ad nos nuper venientes iuxta constitutionem concilii per scripta sua facere promiserunt, et in manu nostra firmaverunt, preterea, sicut de aliis excommunicationibus per legatos Romane ecclesie factis facimus, depositionem et excommunicationem quam Geraldus Ostiensis episcopus cum Rainbaldo in Munionem symoniacum, qui super Symeonem venerabilem fratrem nostrum Ocensem episcopum ordinatus erat, ratam esse decrevimus atque firmavimus, usque dum resipiscens de episcopatu, qui indebite tenuit, sibi satisfaciat atque inde recedat. Dat. Rome XIIII kal. aprilis indictione XII.

APPENDICE 2b: Bula del papa Gregorio VII fechada el 9 de Mayo de 1074, y dirigida al rey Alfonso VI de León-Castilla, tal como esta reproducida en: Mansilla Reoyo, D. (ed.), La documentación pontificia hasta Inocencio III (9651216), Roma, 1955, no.10:

Hispania Sacra, LX

122, julio-diciembre 2008, 685-701, ISSN: 0018-215-X 
Hyspanie Regi

Gregorius episcopus, servus servorum Dei, Adefonso regi Hyspanie et episcopis regni illius, salutem et apostolicam benedictionem.

Notum vobis esse volumus, hunc fratrem nostrum et episcopum Paulum, cognomento Monio, ad apostolorum limina et nostram presentiam venisse, et post redditam rationem earum rerum, quibus eum appellavimus, sicut dignum erat, in vestram communionem et dilectionem receptum fuisse. Romanum ordinem in divinis officiis, sicut ceteri Hyspani episcopi, qui synodo interfuerunt, se celebraturum, et ut melius poterit observaturum promisit. De cetero, quoniam ad preseas omnia, que secum habuimus pleniter expedire et determinare non potuimus, ad futuram synodum cum ad nos iterum reverti precepimus, et super hac re ab ipso prompte obedientie sponsionem accepimus. Quapropter remittentes eum cum litteris nostris caritati vestre commendamus, quatenus et vos una nobiscum eum diligatis, et secum atque inter vos vinculo pacis Christi, in quo per ipsum ad fidem uniti et in sortem hereditatis glorie Dei electi estis, coniuncti firmiter persistatis. Te vero regem ut dilectissimum filium rogamos et ammonemus ut, considerans et ante mentis oculos ponens in quam districto indicio de commissa tibi amministratione rationem redditurus est, regni tui gubernacula in teneda equitate exornare studeas, et huic episcopo antiquam sui episcopatus sedem reparare ac stabilire cum Dei adiutorio modis omnibus insistas.

Deus autem omnipotens ad omnia, que sibi beneplacita sunt, cortuum dirigat, et ea te in presenti vita promereri faciat, unde postmodum sempiterna retribuat. Dat. Rome. VII id. maii indictione XII. 